\title{
2019 冠狀病毒病疫情下的道德
}

\section{議題的初步哲學探索}

\section{A Preliminary Philosophical}

\section{Investigation into Moral Issues}

\section{of the COVID-19 Pandemic}

\author{
陳成斌 \\ Benedict S. B. Chan
}

摘要 Abstract

在 2019 冠状病毒疫情之下, 至少有雨個公共衛生政策的道 德議題變得異常重要。第一, 現時有不少爭議是關於這些抗疫 政策與個人自由的衝突。這是很典型的公共善與個人自由衝突 的道德爭論, 但疫情令這樣的衝突成為直接而迫切的顧虑。第

\footnotetext{
陳成斌, 香港浸會大學應用倫理學研究中心副主任、宗教及哲學系助理教授, 中 國香港。

Benedict S. B. Chan, Associate Director, Centre for Applied Ethics; Assistant Professor, Department of Religion and Philosophy, Hong Kong Baptist University, Hong Kong, China.
}

《中外醫學哲學》XVIII:1 (2020 年) : 頁 89-112。

International Journal of Chinese \& Comparative Philosophy of Medicine XVIII:1 (2020), pp. 89-112.

(C) Copyright 2020 by Global Scholarly Publications. 
二, 這個世界在疫情之前已有很多嚴重的不平等問題, 但現在 有些防疫政策令社會的不平等變得更為嚴重。儘管本文不會為 這雨個道德議題給予肯定的解答, 但會集中探究在討論這些道 德議題的跨學科辯論中, 應該用到甚麼道德推論和基礎, 並會 詳細解釋以下幾個重要理念。第一, 作者會論證, 衛生道德人 權的理念並不能充分地成為解決這些問題的道德基礎。第二, 不純粹用到權利進路的話, 作者會論證應該用到阿馬蒂亞・森 的後果評價和能力進路作為道德推論和基礎。第三, 這雨個由 森提出的理念可以把不同的道德理論和傳統與公共衛生議題 連繫起來。作者會以儒家為道德傳統的例子, 論證如何以後果 評價、能力進路和儒家當中的一些理念與價值, 以此提出一些 可能方向, 去處理上述兩個道德議題。

At least two moral issues of some public health policies have become significant in the COVID-19 pandemic. First, it is arguable that some policies to address the present pandemic conflict with individual freedom. This is a typical moral debate between public good and individual freedom, but the COVID-19 pandemic has made this conflict a more immediate and urgent concern. Second, the world had serious inequality problems prior to the pandemic, and some of the new public health policies have caused more severe social inequalities. Instead of providing definitive answers to these two moral issues, this paper focuses on what types of moral reasoning and foundation should be used in the interdisciplinary debates around these problems. Several ideas are discussed in detail. First, the author argues that the idea of moral human rights to health is not a sufficient moral foundation to solve these problems. Second, the author argues that in addition to the right talk, we should use Amartya Sen's consequential evaluation and the capability approach as the foundation and moral reasoning. Third, the author argues that these two ideas from Sen can connect different moral traditions with public health issues. The author uses Confucianism as an example of a moral tradition, and argues for possible directions to address the moral issues using ideas and values from consequential evaluation, the capability approach, and Confucianism. 
【關鍵字】2019冠狀病毒病疫情 權利 後果評價 能力進路 儒家

Keywords: COVID-19 Pandemic, Rights, Consequential Evaluation, Capability Approach, Confucianism

\section{一、抗疫政策與道德議題}

2019 冠狀病毒病 (Coronavirus Disease 2019, 簡稱 COVID-19) 持續全球大流行, 對全球影響深遠, 它甚至可能是自 1918 年 H1N1 流感大流行而來, 對世界公共衛生最為嚴重威脅的一種呼吸道病 毒。各國由 2020 年初開始便忙於應對此病毒帶來的禍害, 而應對 的方法, 又會涉及到病毒流行的趨勢, 以及對每個人健康的影響。 特別是現時並沒有 COVID-19 疫苗的情況下, 非葯物干預措施 (Non-Pharmaceutical Interventions, 簡稱 NPIs) 的成效便在現階段 至為重要。這些措施旨在減低人群的接觸, 從而減少病毒的傳播。 然而, 這些措施單獨實施起來一定成效有限, 需要多種干預結合 才能有效果, 而多少市民願意配合這些措施, 也是當中至為關鍵 的元素。這裡可以兩種基本策略為例子以説明之。緩解 (Mitigation) 策略不能阻止病毒的傳播, 但可以減慢, 免得醫療需求在短時間 內大幅提高, 使得社會的醫療系統不勝負荷。當然, 緩解策略也 同時會把醫療資源傾向保護那些老弱和已經患有嚴重疾病的人, 免得這群最有可能出事的人受這種病毒感染。另外一個例子則是 抑制 (Suppression) 策略, 是要扭轉疫情的增長, 令社會減少病例 並且盡量維持在低水平。這些策略, 落實執行時通常都涉及不少 公共衛生政策, 例如進行檢測後, 把相關人士隔離及觀察, 結合 整體人口的社會隔離, 例如關閉中小學和大學、不准許食肆、娛 樂場所、甚至一些商場營業和進行各式活動等。這些公共衛生政 策既可以減少高峰期的醫療需求和減低死亡人數, 亦可以拖延時 間, 讓各國有更多機會成功研製疫苗。如果完全沒有這些干預和 
介入措施, 推測情況可以壞至在短期內會有大量人士受感染和死 亡 (Walker et al. 2020)。由此可見, 這些措施是人類面對今次疫情 的必要公共衛生手段。

然而，同樣無可否認的是，這些政策有不少副作用和後遺 症, 而且成效能維持多久也是疑問。例如有英國研究在 2020 年 3 月時指出緩解策略雖然可以使高峰期的醫療需求的壓力減少三分 之二, 死亡人數減半, 但還是可以導致數十萬人死亡 (Ferguson et al. 2020)。至於抑制策略, 如果疫苗太遲出現, 便可能很難長期維 持，畢竟這些措施對社會、經濟、民生、甚至人身自由等等影響 甚大。然而, 一旦放寬措施, 病毒的傳播可能會迅速反彈, 結果 全球要不斷在張弛之間擺盪, 形成惡性循環, 這些措施能否長期 有效, 實在令不少人產生疑問。這些措施導致社會要付出的社會 和經濟成本, 則更是無法計算了。這也導致了世界各地貧富懸殊 和資源分配不均的問題，顯得更為迫切而嚴重。

以上這些問題，不少都是醫學、公共衛生、社會科學等的問 題, 但當中有一些卻是倫理學的問題, 或者至少倫理學和哲學可 以參與其中的。當中特別以 (1) 公共衛生政策與人身自由的衝突, 與及 (2) 疫情下的公共衛生政策導致的經濟不平等問題, 最為與 哲學和倫理學息息相關。我們到底應以怎樣的哲學與倫理思維去 處理這兩大問題呢? 如此複雜的題目, 不可能以一篇文章的篇幅 去完全解答所有問題, 但至少, 在以下的章節裡, 筆者會嘗試提 出一些框架和方向, 作為初步的哲學探索, 好讓我們現在和將來 面對以上提到的兩個問題時, 可以如何由各地的宗教與社會道德 理論與傳統, 特別是儒家思想, 去思考如何解答 COVID-19 全球 疫情下的公共衛生政策所導致的一些道德問題。

\section{二、公共衛生政策與權利的爭議}

要理解公共衛生政策的各種倫理議題, 可以先由疫苗 (Vaccine) 與群體免疫 (Herd Immunity) 的道德議題説起。總體來 
説, 研發甚至強制接受疫苗有時也是公共衛生政策的一部份, 因 此談論疫苗並不離題。然而, 當討論集中在現階段與 COVID-19 疫情有關的部份, 疫苗的問題會比一般情況複雜。首先, 截至 2020 年 8 月初 (亦為本文完成的時間)，全球還未能成功研發出針對 COVID-19 的疫苗。此外, 現時不少疫情下的公共衛生政策, 其 目的不完全在於消滅病毒, 而是拖延群眾感染病毒的時間, 避免 一次過太多人感染。而最終的目的, 是希望能有足夠的時間研發 出疫苗, 並且同時社會內有足夠的人口對病毒有抗體 (不論是因 為疫苗還是因為自然產生抗體) 。由此可見, 一些措施的最終目 的, 還是與群體免疫有關。因此, 儘管不少非藥物干預措施(NPIs) 並非直接與疫苗相關 (疫苗已經是藥物干預措施的範圍), 我們還 是可以不妨由疫苗和群體免疫的倫理議題開始我們的討論, 再以 此推論開去。那麼, 我們應該用甚麼道德原則的框架去討論呢? 在此, 我們可以借用 Gopal Sreenivasan (2012) 的論證, 去解釋為 何衛生道德權利 (Moral Rights to Health) 不足以作為這樣的道德 原則的框架, 然後再由當中的不足思考可以用甚麼其他的道德理 論作為處理這些道德議題的方向和框架。

Sreenivasan 本身並非反對道德權利的重要性。相反, 他是道 德權利的擁護者。但亦因此, 他在與 Johnathan Wolff (2012) 辯論 衛生人權 (Human Rights to Health) 時, 明確反對將衛生人權視為 道德權利。這既與道德權利的特性有關, 亦與衛生或健康的特性 有關。道德權利的部份, 大約就是説, 當一位權利擁有者 (Right-Holder) 擁有一項事物 $\mathrm{x}$ 的權利時, 其他的行動者 (Agents) 就有責任去確保權利的擁有者擁有 $\mathrm{x}$ 。然而, 不少學者, 例如 Sreenivasan, 都會堅持道德權利當中的權利擁有者、行動者、和 責任都要有明確的界定和標準 (有些人是同時要求三者, 有些則 只要求其中一兩項); 然後 $\mathrm{x}$ 就是變數, 指向不同事物, 看看甚麼 事物能符合這些高要求的界定和標準。一般來説, 在這種理解下 的道德權利, 都是屬於廣義的義務論進路 (Deontological 
Approach)，亦即是義務式或絕對式的道德權利（Absolute Moral Rights), 有絕對的標準和嚴格的約束 (Constraints)。在這樣高要求 的標準和約束下, 只有很少事物可以通過重重檢驗而成為道德權 利; 有些道德哲學家甚至認為根本沒有這樣的權利。衛生固然很 重要, 卻無法滿足三者的要求, 特別是到底有責任的行動者是誰, 而要負的責任又只是不完全責任 (Imperfect Obligations) 的話, 這 樣衛生是難以成為道德權利的 (Sreenivasan 2012,243-250; O’Neill 2005)。

除了從道德權利的特性著手外, 我們也不妨從群體免疫作為 公共衛生一環的特性入手 (Dawson 2007 ; Malone and Hinman 2007)。群體免疫都有著一些公共物品 (Public Goods) 的特質, 例 如「非競爭性」(Non-Rival)、「非排他性」(Non- Excludability)、 和「不可分割性」(Indivisibility) 等。這裡説的非競爭性, 是指該 物品即使被一人享用了, 也不會減少另一些人享用的機會。非排 他性, 是指不會排除其他人使用的權利。而不可分割性, 則是指 每個人享用此物品時都是享用此物品的全部而非部份。群體免疫 就是有著這些特性 (Sreenivasan 2012，255)。群體免疫作為公共物 品的話, 會讓我們發現, 即使真的有衛生的道德權利, 亦不足以 支持政府有道德責任令社會有足夠的人口有免疫能力。這不代表 這種道德責任不重要, 只是當道德權利作為義務式的權利時, 便 不足以支持這樣的道德責任。因此, 重要的是我們應該需要道德 權利以外的道德原則和框架去支持這種責任, 而非因此而斷定群 體免疫不重要, 或者群體免疫的道德責任不重要 (Sreenivasan $2012,254-259) \circ$

此外, 儘管 Sreenivasan 並沒有直接提出以下的想法, 但筆者 認為, 只要我們有清楚的原則和框架去支持群體免疫的道德基 礎, 那麼即使在這樣的理論當中, 仍然容許衛生權利作為要求式 的權利 (Claim Rights)，亦即有些行動者有相關推廣和保障衛生的 責任, 其實並無不可。重點是要先弄清楚那個道德的大原則和框 
架, 而道德權利並非當中唯一或最重要的基礎, 而只是當中的一 部份。由此路進, 應該可以處理得到群體免疫的道德議題。

以上是對群體免疫的初步討論。既然不少疫情下的公共衛生 政策本身就有著和群體免疫一樣作為公共物品的特性, 又或者是 與疫苗一樣要達至群體免疫這目的的手段, 或者至少是為著防止 促進疫情和促進衛生健康等目的, 那麼我們可以在這角度下把它 們放在一起討論。也就是説, 衛生的道德權利同樣不足以作為支 持疫情下的公共衛生政策的道德原則的框架和基礎, 而需要另外 的道德理論去支持。那麼, 我們接下來需要討論的, 就是甚麼樣 的道德理論, 或者至少是擁有甚麼道德特性的理論, 才足以成為 基礎。

這裡説的道德理論，既可以是例如效益主義、康德倫理學、 德性倫理學這些在道德哲學中常常提到的哲學理論, 也可以指一 些宗教或社會內的道德倫理傳統, 例如基督教、佛教、儒家等等。 這些哲學理論或者道德傳統都在世界不同的地方有著悠久的歷史 和豐富的道德資源, 若然能好好運用的話, 當能為我們提供很多 有用的觀點; 而在討論不同社會文化時, 有些理論和傳統更是不 能忽略的, 例如在東亞社會, 儒家對生物倫理學 (Bioethics) 和醫 學倫理學 (Medical Ethics) 的應用就是一個很好的例子 (Fan 1999 及 2010)。然而, 由道德理論或傳統去到一些實質的公共衛生議 題 (例如隔離措施、疫苗、群體免疫等的道德議題), 中間其實還 需要補上各種道德推理、論證、價值、和信息焦點 (Information Focus) 等等, 不然恐怕是無法把道德理論和傳統直接應用到那 些公共衛生議題的。

當然，這樣的大題目，並非三言兩語可以説清。由於篇幅所 限, 所以本文只會集中討論兩類重要的理念, 是在討論如何應用 道德理論或傳統去處理疫情下的公共衛生政策的道德議題時不可 或缺的。這兩類特性, 一類是「後果式評價」(Consequential Evaluation), 另一類則是「能力的進路」(Capability Approach)。 
兩者都是由 1998 年諾貝爾經濟學獎得主阿馬蒂亞 ·森（Amartya Sen）提出的。以下先介紹這兩種特性, 然後再論證如何以此上接 不同道德理論或傳統, 下接指導當前的公共衛生政策的道德議題 的方向。

\section{三、後果式評價}

森是百科全書式的學者, 在不同的課題上都有著豐碩的研究 成果。儘管與他其他著名的研究 (例如飢荒與發展) 相比, 他的後 果評價研究沒有那麼廣為人知, 但其實他大部份的研究題目 (包 括下一節談論的能力進路) 都可以與他的後果評價研究有關 1 。要 討論後果評價, 就要談談森的研究與後果論 (Consequentialism) 甚 至效益主義 (Utilitarianism) 的分別。

上一節提到，諸如群體免疫的公共衛生問題很難用道德權利 的框架來處理。對道德哲學稍有認識的人, 自然會想到道德理論 的另一流派, 就是後果論, 亦即是以世界情狀（States of Affair， 即世界上所有人和事的狀態）的好壞作為判斷對錯的唯一標準的 理論。在眾多後果論當中, 又以效益主義為當中的佼佼者。效益 主義欲以一簡單的公式去囊括所有的道德判斷, 野心不可謂不 大, 然而也導致了很多問題 (Smart and Williams 1973; Williams and Sen 1982 ；Scheffler 1988 及 1994)。簡單來説，如果以效益主義來 處理疫情下的公共衛生政策的道德議題, 就算可以解決當中部份 問題, 也會帶來更多無法解決的難題, 因此未必可取。

然而，森提議的後果評價，卻不完全是效益主義，亦不是上 述定義下的後果論。後果評價基本上不是整全的道德理論 (Comprehensive Moral Theory)，而是一種道德推論或者實践理性 (Sen 2000)。這種推論要求的, 是在做道德推理或實踐理性時, 不

（1）有趣的是, 儘管森寫了大量與後果評價有關的文章, 但他在西方並沒有一本 以此為主題的專著或者文集。反而在中國曾經出版了一本文集, 收錄了他在 這方面的研究文章的中文翻譯本 (阿馬蒂亞・森 2006)。 
可能忽略世界情狀的好壞來評估對錯, 而且每個人亦要為自己的 選擇所帶來的後果負責。因此, 後果評價並不完全是後果論, 或 者頂多只能算是弱版的後果論, 因為後果評價並沒有要求把世界 情狀的好壞視為對錯的唯一標準, 而只是要求不能忽略評估後果 的好壞 (Sen 2000，477-478)。

當我們把後果評價與效益主義相比時, 也會發現後果評價是 與效益主義相容的，但不完全等同。森把效益主義分為三部份， 而後果評價只是當中的一部份。除了後果評價外, 效益主義還另 外加入了「福利主義」(Welfarism) 和「總和排序」(Sum Ranking) 兩部份。所謂的福利主義, 是指「關於各種備選事態相對善性的 判斷只能根據這些事態各自的個人效用總和, 並且必須是該總和 的遞增函數」，而總和排序則是「一種效用總和至少與另一種同 樣地善, 當且僅當, 前者至少與後者同樣地大」（阿馬蒂亞·森 $2006 ， 6)^{2}$ 。簡單來説, 福利主義已包括了我們平常聽到的經典效 益主義內的享樂主義 (Hedonism) 傳統, 亦即務求把幸福最大化; 而總和排序則視每個個體均等, 並且以每個個體的幸福加起來的 方式計算總值。森認為, 反對者對效益主義的主要挑戰, 其實都 集中在福利主義與總和排序之上。然而, 後果評價本身卻不一定 要與此兩者掛勾。如果粘除了這兩種要求, 後果評價與效益主義 相比起來，其實是可以海闊天空，有無限的可能。

例如上一節提到的（義務論式）的道德權利要求太嚴格，是 絕對的約束, 令很多重要的價值 (例如公共衛生) 都不能成為嚴格 意義下的道德權利。效益主義者處理此問題的方法是把道德權利 完全工具化，只把道德權利視之為促進幸福的工具，但這樣的處 理方法嚴重弱化了道德權利的重要性。森則走中間道路, 以後果 評價為推理的基礎, 認為可以把一些道德權利視為幸福之外的重

(2) 原文為: “Welfarism: The judgment of the relative goodness of alternative states of affairs must be based exclusively on, and taken as an increasing function of, the respective collections of individual utilities in these states." "Sum-ranking: One collection of individual utilities is at least as good as another if and only if it has at least as large a sum total." (Sen 1979, 468) 
要價值 (亦即可以帶來好的後果), 而這樣直接把道德權利視為好 的後果, 就可以避免了把權利工具化的問題。另外, 因為這樣的 道德權利還是在後果評價的系統內, 要與其他的後果比較, 不一 定是絕對的約束, 這樣的權利, 便可以納入諸如教育或衛生健康 等價值 (Sen 1982 及 $2000 ， 492-498) 。$

誠然, 這樣的系統是有利亦有弊的。其缺點亦是因為包容性 太大, 變得猶如甚麼都可以當成是良好的後果, 這樣的話便會流 於道德虛無或者相對主義。一些哲學家就曾指出這個缺點, 例如 Judith Thomson 在與 Martha Nussbaum 討論後果評估時便指出效 益主義反而有明確的道德價值 (幸福感) 去判斷好壞, 但後果評 估卻似乎內容空洞, 説了等於沒説 (Thomson 2001 ; Nussbaum 2001)。

然而, 正如上面所説, 後果評價本身只是道德推理的方法, 不是整全的道德理論。要知道後果是好是壞, 就需要和其他的道 德理論和傳統「合作」。也就是説, 這種推理方式的優點是可以 容納很多不同的道德價值與理論, 例如後果評價不僅可以嵌入後 果論或者效益主義成為當中的一部份, 亦可以嵌入某些版本的義 務論, 也就是任何不排斥要考慮後果, 但不用以此為唯一判斷標 準的義務論; 這基本上就等於與絕大部份版本的義務論相容, 只 會與例如羅伯特 - 諾齊克 (Robert Nozick) 的「基於（權利）約束 的義務論」 (Constraint-Based Deontology。這是森的描述) 不相 容 (Nozick 1974 ; Sen 1982 及 2000)。有些學者亦認為, 即使如康 德的道德哲學, 也一樣可以從後果式的思維入手的 (Cummiskey 1996)。

後果評價也可以與不少宗教及社會的道德傳統相容。就以在 東亞地區特別重要的儒家為例子; 儒家本身已有著很豐富的形而 上學、後設倫理學、規範倫理學、應用倫理學等的基礎及資源。 在儒家內部的討論當中, 有不少論證都可以與廣義的後果思維有 關。過去的朱陳之辯, 令到當今有學者認為儒家當中有一支可算 
是後果式甚至效益式的儒家 (Utilitarian Confucianism) (Tillman 1982); 也有人討論例如早期儒者或者孟子的思想與後果論的關係 (Im 2011 ; Yunping 2005), 又或者是儒家當中的德性與後果的關 係等 (Ivanhoe 1991; Anderson 2011)。誠然, 整體上儒家思想很難 被視為後果論, 上述的研究也有不少爭議, 引來不少人辯論 (Keown 1996 ； D’Ambrosio 2015)。總的來説，儘管儒家本身不是 後果論的一支, 但這不代表不能把後果評價嵌入當中, 甚至令兩 者相容。至少, 對後果評價這種道德推理來説, 實在沒有理由抗 拒好像儒家思想那樣的道德傳統。

這樣與大部份的道德理論與傳統相容的特性, 可説是後果評 估的其中一項優點, 亦有助我們在推理當中進一步斷定後果的好 壞。當然, 如果我們想要把公共衛生措施當中的價值視為良好的 後果, 似乎除了基於後果評價外, 還有更多的細節需要交待。下 一節討論的能力進路正是為此而設。

\section{四、能力進路}

能力進路可算是森對哲學的貢獻當中最為人所知的一個進 路。能力進路由森所開創和提出, 但經過這數十年來的發展, 已 經被不少其他人豐富了當中的內容, 而且和森原初提出的版本頗 有不同。例如上一節提到的 Nussbaum 亦是能力進路的另一奠基 人, 她由亞理士多德的哲學發展能力進路, 並提出十種不同的中 心能力 (Central Capabilities), 和森的想法有些差異 (Nussbaum 1988、2000 及 2011)。然而, 因為篇幅關係, 這裡我只會主要討 論森的版本; 其他人對能力進路的貢獻則只會在有需要的時候才 會提及。

首先, 我們要留意的是, 這裡説的「能力」(Capability) 是 一個技術詞語, 與日常的理解稍為不同。能力進路裡所講的能力, 是指人類有自由去實踐各樣的功能 (Functioning)。如森所言, 「採 取這個詞是為了表示個人能夠做或成為的事物的不同組合一一他 
或她能夠獲得的各種 “功能”」(阿馬蒂亞 - 森 2006，227)。森之 所以要提出這個技術性的概念, 並非純粹無中生有, 而是最初是 要修正和改善約翰·羅爾斯 (John Rawls) 在《正義論》 (A Theory of Justice）裡面提出的「基本物品」（Primary Goods），但及後 發現「能力」本身就可以是道德及政治哲學的實質理論裡面的很 好的價值和信息焦點 (Information Focus)。一邊廂, 效益主義用主 觀的幸福感（或類似的對「效用」的解釋，例如福利）作為信息 焦點去判斷對錯, 另一邊廂, 亦有不少理論 (例如經濟學) 會用 到客觀的資源、收入甚至財富作為信息焦點去做總體的計算與衡 量。與效益進路或資源進路不同的是, 能力進路要在中間取得平 衡, 並且以自由作為基礎, 讓每個人有自由去選擇如何實踐不同 的功能 (Sen 2009, 231-235)。

森最初提出能力進路, 就是為了回應 $「$ 甚麼的平等」(Equality of What) 的問題, 而答案就是能力 (Sen 1980、1993、1985 及 1992)。 除了平等問題外, 能力進路也與很多不同的道德哲學議題相關, 諸如權利、人權、公義等等 (Sen 1984、2004 2005 -2006 及 2009)。 另外, 能力進路也是森談論人類發展（Human Development）的 基礎。一般而言, 人們對發展的理解, 直覺會是關於經濟發展。 經濟增長固然是提高人類生活質量的重要元素, 但人類發展似乎 亦應包含一些經濟增長以外的概念。例如現時聯合國使用的「人 類發展指數」（Human Development Index），除了計算人均國民 總收入外, 亦會同時計算受教育年限與出生時的預期平均壽命, 也就是用上經濟、教育、與衛生三組指標去計算社會的發展指數。 聯合國的這個指數, 背後的指導思想正是能力進路, 而森也是這 個指數其中一位創立者。由此可見, 能力進路可以在眾多不同的 道德與政治哲學議題上作出重要的貢獻。

筆者要在這裡談到能力進路, 背後是有兩個原因的。首先, 能力進路明顯地是可以應用在公共衛生議題之中。除了森外, 不 少同意能力進路的學者, 都有嘗試用不同的方法連結能力進路與 
公共衛生議題。例如 Jennifer Ruger（2010）借用了 Nussbaum 與 亞里士多德談功能與能力的角度來討論公共衛生與社會公義; Sridhar Venkatapuram (2011) 則論證健康是後設的能力 (Meta-Capability), 並以此來討論公共衛生的公義。總而言之, 能 力進路與衛生或健康的議題息息相關, 自然是在討論疫情不可或 缺的學問。另一個討論能力進路的原因是, 雖然能力進路內有不 少人都有討論公共衛生議題, 但他們都鮮有用到後果評價的進 路。儘管森是能力進路的奠基者, 而在能力進路陣營內的學者都 是言必及森, 但用後果評價的方向來處理能力的學者卻不算太 多, 至少不是能力進路陣營內的主流。或者可以説, 把兩者結合, 正是森的哲學比較獨特的地方，值得向大家説明和推薦。

雖然與後果評價比較起來, 能力進路並不是那麼明顯地可以 與不同的道德理論與傳統相容, 但事實上能力進路的彈性和可塑 性也是很大的。Ingrid Robeyns 就認為, 能力「進路」(Approach) 與 能力「理論」(Theory) 不同; 後者才是獨具一幟的完備理論, 但 進路則可以容納不同版本的理論和傳統 (Robeyns 2016 及 2017)。 Nussbaum (1988) 早期會用到亞理士多德的哲學去建立能力進 路, 後期則多用羅爾斯的政治自由主義 (Nussbaum 2006 ; Rawls 1993)，這些都與森的後果式評價的能力進路有些分別。而 Mozaffar Qizilbash (2008) 則討論了不同版本的後果論如何能與能 力進路相容, 認為森的後果評價不夠徹底地實踐後果論, 所以他 論證如何能建立「能力式的後果論」(Capability Consequentialism)。

至於與儒家思想的關係, 現時較少學者從儒家的角度討論能 力進路, 但在能力進路的一方, 第一代的學者如森和 Nussbaum 等人在討論人類發展的時候也有談論過不同文化的重要性。森更 曾引用過孔子和毛澤東來支持他的想法 (Sen 1999)。Nussbaum 早 期的能力進路建基於亞理士多德的學説, 而比較亞理士多德與儒 家則是比較哲學內的顯學 (下一節會談到更多), 有興趣的學者可 以由此路進以研究能力進路 (Nussbaum 2000、2006及 $2011 ; \mathrm{Yu}$ 
2007)。而近年來也開始多了學者在能力進路與人類發展的陣營內 引進東亞的觀點 (Chan 2019a \& b ; Drydyk and Keleher 2019)。在 這個角度而言, 至少能力進路本身並不排斥其他道德理論和傳 統, 可以在一定程度上, 特別是要在應用到某些道德議題時, 作 為有用的理念來處理相關議題。

\section{五、實踐理性的應用 : 從儒家到疫情下的 公共衛生政策的道德議題}

在第一節, 筆者曾提及, 疫情下的公共衛生政策至少有兩個 道德上的難題：(1) 政策與個人自由之間的衝突；(2) 政策措施導 致的經濟不平等問題。現在走筆至此, 我們已知道不能只用義務 式或絕對式的權利作為道德框架, 但我們可以用後果評價與能力 進路協作不同的道德與社會哲學理論傳統的框架去處理問題。當 然, 此篇文章只是初步的哲學探索, 不可能為這些問題提供很細 緻的答案。事實上, 要為這些問題提供答案, 應該不只是哲學或 倫理學的事, 而是跨學科的研究。然而, 這裡還是可以提供一些 道德思考方向, 讓我們在進行跨學科研究時有較清楚的哲學指 引。以下筆者會以一些由儒家思想而來的重要價值為例子, 㘓釋 如何處理這些道德議題。

這裡要由儒家提倡的一些德性 (Virtue) 説起。談到德性, 很 自然會想到德性倫理學（Virtue Ethics）。1958 年「現代新儒家」 發表了《為中國文化敬告世界人士宣言》, 而同年 G. E. M. Anscombe 亦提倡重新審視和發揚德性倫理學 (Anscombe 1958 ; Chang et al. 1958)。近年有不少學者以此為各自的出發點, 去比較 儒家與德性倫理學（Angle and Slote 2013）；另外亦有學者比較 先秦儒家與古希臘的哲學（如上一節提到的余紀元） (Yu 1998 及 2007），又或者是直接討論一些德性的概念（Van Norden 2007）， 
甚至認為由此路進, 儒家可以在全世界成為廿一世紀德性倫理學 甚至是倫理學的主流（Slote 2015）。

篇幅所限, 這裡無法把以上的方向全部都討論到。而事實上， 討論德性, 也不一定要由德性倫理學入手, 畢竟德性本身的重要 性, 也是跨越不同的道德理論及傳統的, 例如 J.S. Mill 也有討論 德性並非只是達至幸福或快樂的手段, 而是幸福當中的一部份, 以此來把德性融入效益主義之中（Mill 1863，Chapter 4)。與其讓 我們在這裡比較儒家和德性倫理學（甚至效益主義）這麼龐大的 題目, 倒不如集中討論儒家的德性, 再與其他道德理論傳統當中 的德性一併討論。

我們可以由《論語·述而》的「志於道、據於德、依於仁, 游於藝。」説起。根據余紀元的講法, 孔子的目標就是尋求「道」, 也要培養「德」（余紀元 $2009 ， 47$ ）。這種「道」，是形而上或 本體的道, 也是終極目標; 而「德」則是德性。另外, 人的德就 是仁；一個有德之人也是一個仁者（余紀元 2009，53）。從這樣 的理解出發, 可以把儒家的「道一德」的框架與古希臘哲學的「幸 福 (Eudemonia) 一德性」框架比較（余紀元 2009，41-89），亦可 以在人性問題上把儒家談的「性」與亞里士多德的「功能」比較。 而在談論人性的問題上, 便應該要加入孟子的「性善論」以補充 孔子的講法（余紀元 2009，90-129）。這裡不得不提《孟子.公 孫丑上》談到的一段重要思想：

孟子曰：「人皆有不忍人之心。先王有不忍人 之心，斯有不忍人之政矣。以不忍人之心，行不忍 人之政, 治天下可運之掌上。所以謂人皆有不忍人 之心者, 今人乍見孺子將入於井, 皆有忧惕惻隱之 心。非所以内交於需子之父母也, 非所以要譽於鄉 黨朋友也, 非惡其聲而然也。由是觀之, 無惻隱之 心，非人也；無着惡之心，非人也；無辭讓之心， 非人也；無是非之心，非人也。惻隱之心，仁之端 也; 羞惡之心，義之端也; 辭讓之心, 禮之端也; 是非之心, 智之端也。人之有是四端也, 猶其有四 
體也。有是四端而自謂不能者, 自賊者也; 謂其君不能 者, 賊其君者也。凡有四端於我者, 知皆擴而充之矣, 若火之始然, 泉之始達。苟能充之, 足以保四海; 苟不 充之, 不足以事父母。」

孟子以見擩子入井而有側隱之心或不忍人之心去談四端與仁 義禮智的關係, 是孟子其中一段最著名的講法, 亦把儒家性善論 由人性到德性的看法很清楚的表達了出來。這是任何談論和比較 儒家的德性與其他思想時不可忽略的道理。

對於這些比較哲學的做法, 有些學者會持有異議, 例如 MacIntyre (1991) 就認為儒家與古希臘思想各自有不同的傳統, 兩 者是不可通約的（Incommensurable）。誠然, 如儒家思想這樣有 著悠久歷史傳統的思想, 當中一定有其獨特性, 是很難約化或抽 離脈絡, 當成是其他道德理論 (如德性倫理學) 的一部份。然而, 這是否代表這就是不可通約的, 卻頗有爭議。而就這裡的討論來 説, 更重要的問題是, 就算真的是不可通約, 也不代表當中的價 值是不可比較的（Incomparable）。在我們當前是面對疫情, 要制 定公共衛生政策; 我們不可能把整套道德理論或者傳統放入去， 那麼要拿取當中甚麼的價值來制定政策, 便很值得思考。特別用 到後果評價與能力進路, 就是當中很重要的道德推理過程。技術 上，後果評價其實是容許不完整的排序（Incompleteness of Ranking），因此是可以在特定情況下比較不可通約的選項 ${ }^{3}$ 。在 這情況下, 儒家思想提倡的德性, 會是這個道德推理裡面很重要 的價值。

首先，對於政策的成效與個人自由的衝突的問題，我們可以 循以下的方向去思考。不少政策措施都是為了延緩和抑制病毒的 傳播, 實在是無可厚非並且無可奈何之舉。這是與疫苗和群體免 疫的情況相類。不過, 措施實行太久, 不只會令到所有人都很不

(3) 這涉及到後果評價只要求最大化 (Maximization) 而非最優化 (Optimization) 這技術上的分別。這分別以及比較不可通約的選項的問題, 可參考(Sen 1997 及 2000; Nussbaum 2001)。 
方便, 影響大家的身心健康, 亦令社會停擺, 代價十分之大。在 這樣的兩難裡, 我們固然不能簡單地説政策措施本質上就是違反 了個人的權利或者如政治哲學家以賽亞 ·柏林（Isaiah Berlin）所 説的消極的自由（Berlin 1969），因為在疫情之下，病毒某程度 上也是在侵害我們的自由, 至少是我們積極的自由。可是, 我們 也不應該任由政府或社會把公權力無限地擴張, 甚至以對抗疫情 之名而行獨裁之實, 打壓人民一般的自由。而這些問題是消極自 由或者義務論式的道德權利所無法涵蓋的。在這問題上, 我們不 妨用到後果評價, 而當中要評估的後果則是能力。事實上, 森自 己也認為他談到的能力是與積極自由息息相關（Sen 1982， 38-39)。以能力作為信息焦點和評價後果好壞的標準, 審慎評估 各種措施對能力會有甚麼影響。比方説, 居家限制會怎樣影響我 們各種能力呢? 這會限制了我們移動和社交的能力, 但換來避免 了染病喪失了的各種能力, 甚至生命 (其實生存或生命在技術上 也算是一種能力)。當然, 如果隔離太久和程度太強, 也有可能會 得不償失的。比方説, 如果我們發現室內地方比起室外更有機會 令人感染病毒, 那麼公共衛生政策便應該對室內的情況更有針對 性, 而不是倒行逆施地不限制室內聚會人數, 卻限制室外聚會人 數。這些都要很仔細和審慎的評估。而其中可以用到的道德價值, 可以是應該如何在可能範圍內盡量減少大家受到的傷害。

由此路進，我們便可以加入不同的道德與政治理論傳統，將 之應用在現實情況中。所謂要減少傷害, 並非只是享樂主義或效 益主義者的專利（當然他們也很強調要減少大家的傷害）。例如 基督教內提到的好撒瑪利亞人的故事, 近年便被一些學者引申論 證為減少傷害是我們的基本道德責任, 並以此來討論一些道德議 題（Delmas 2014 ; Wellman 2005）。在東亞社會, 儒家思想還是 有著很重要的位置。在考慮這些問題時, 便可以同時考慮到在儒 家社會裡, 儒家思想會怎樣影響到我們思考公共衛生措施與個人 自由之間的張力。而在減少大家傷害的方面, 上面提過孟子説的 
惻隱之心或不忍人之心, 絕對是這種減少傷害的思想的道德基 礎, 而且背後包含的訊息甚為豐富, 由上面提及的形而上的「道 與德」的框架（不只是道德，而是形上的道，還有人的德性）, 到每個人的仁心，不僅豐富了積極自由的內容, 更讓人們明白為 何要盡量避免和減少大家的傷害。簡而言之, 儒家在惻隱之心到 四端的講法, 不只是豐富了自身德性仁心的內容, 也可以為減低 傷害的道德原則與後果提供基礎, 完善了我們在這方面的道德推 理。

至於第二個道德難題，亦即因為疫情的公共衛生政策措施而 導致的不平等問題, 推理上也是要用到後果評估與能力進路的, 亦由此可以把儒家的德性包括入來。首先, 正如上兩節提及的, 所謂的不平等，實質的資源（如財富）分配不均固然是大問題， 但始終財富資源等等只是工具; 真正的根本問題, 是因為資源匱 乏會影響人類的能力與發展, 帶來不良的後果。事實上, 針對 COVID-19 疫情的不平等問題, 森也在一些報紙評論中明確呼篔 各國要小心處理（Sen 2020a \& b ）。由於能力進路本身就是以處 理不平等問題起家的, 而後果評價也是森的能力進路的重要一 環, 以此來處理疫情下的不平等問題, 似乎是很合理的方向。

另外，這樣的道德推理，也不能忽略了各種上文提及過的道 德與政治的理論與傳統, 例如儒家思想, 可以與後果評價及能力 進路合併在一起去處理問題。首先, 其實資源不平等的問題, 也 可以與上述提到的減少傷害的道德責任延伸開去, 例如彼得 - 辛 格便以此來論證大家對全球貧富不均有著道德責任（Singer 1972）。而在儒家內, 例如《論語 - 季氏》便有「不患寡而患不 均」的想法。由《禮記 - 禮運》對大同與小康的描述，到《孟子. 滕文公上》的「方里而井, 井九百畧, 其中為公田。八家皆私百 畧, 同養公田。公事畢, 然後敢治私事, 所以別野人也」, 皆可 見儒家對資源不平等其實也有很豐富的討論, 背後也是基於仁義 等德性的。要談論經濟不平等, 便不能忽略儒家這方面的思想。 
由於本文旨在建立一套道德推理的框架去回應疫情的問題， 所以不少討論政策的細節只能在此從略。然而, 在本文結束之前, 理應回應幾點可能的質疑, 以説服讀者為何要用到這樣的哲學去 處理疫情下的道德議題。

首先, 很可能有人會質疑, 如此談論儒家的德性思想, 會否 變成好像只在抽取有用的部份, 破壞了儒家的整全性和主體性? 由這角度去看, 甚至可以質疑, 這樣的框架會破壞了各種道德理 論與傳統, 好像雜家那樣取百家之長, 但沒有了內部思想的統一 性。要回應這個質疑, 我們必須理解, 正如本文早前所説的, 後 果評價和能力進路並非整全的學説, 只是實踐理性的道德推理方 法, 本身和各種道德理論和傳統並沒有衝突。事實上, 這些推理 方法當中也沒有太多的道德價值觀和內容, 需要各種理論和傳統 來填補當中的空隙。可以説, 後果評價和能力進路只是用來成就 各種理論和傳統如何可以應用到公共政策, 並不會破壞例如儒家 思想的主體性和整全性。

如此, 另一些人可能又會質疑, 既然我們還是需要儒家的主 體性和整全性, 那麼為甚麼我們要花那麼多時間討論後果評價和 能力進路, 去建立那樣的一個實踐理性的框架, 而不是直接把整 套儒家應用在疫情的公共衛生政策之上呢? 然而, 我們要明白的 是, 這樣的公共衛生議題, 是跨學科的題目, 道德理論和傳統雖 然可以在制定政策當中佔有一席之地, 但很難直接把整套思想應 用到疫情問題之中, 至少必須經過一些轉化。這也是後果評價和 能力進路的好處, 可以保存儒家思想的主體性和整全性的同時, 亦可以把當中有關的部份轉化出來, 與其他學科整合。

這樣的進路, 另一好處是可以避免了很多在比較哲學當中的 爭議, 例如比較儒家與古希臘思想、效益主義等的異同、甚至誰 優誰劣等。當我們只是要以後果評價和能力進路來考慮時, 不少 價值都可以在不同的道德理論中找到一些共識。例如上面提及的

「減少傷害」這種道德價值, 既是良好的後果, 各種理論和傳統 
都有其獨特的原因證成（Justification）此價值，例如我們可以用 儒家的性善論和惻隱之心去解釋為何我們應該盡量減少對別人的 傷害。這樣既保存了儒家的獨特性，同時提供一個應用到疫情問 題的道德推理的框架, 可説是後果評價和能力進路的優勢。

總結來説，在 COVID-19 疫情下的公共衛生政策措施，會帶 來至少兩個道德哲學的問題。儘管本文的目的不在解決這些問 題, 但至少討論了可以用甚麼道德哲學的框架來處理, 也就是以 森的後果評價與能力進路去處理相關的議題。在這樣的框架裡, 例如儒家的惻隱之心和各種仁德，還有不患寡而患不均等思想， 都可以成為討論政策當中的重要道德基礎和價值。也就是説，這 套框架上可以與不同的宗教及社會道德理論或傳統（如儒家）掛 勾, 下可以應用到不同的地方的情況之中, 去解決各種問題。因 此，我們值得對此深思，在儒家思想和如此的實踐理性的框架之 中，繼續去探索當中的哲學意義。

\section{參考文獻 References}

余紀元, 林航譯: 《德性之鏡——子與亞里士多德的倫理學》, 北京： 中國人民大學出版社, 2009 ○ YU Jiyun. The Ethics of Confucius and Aristotle: Mirrors of Virtue, translated by LIN Hong (Beijing: China Renmin University Press, 2009).

阿馬蒂亞·森, 應奇譯: 《後果評價與實踐理性》, 北京: 東方出版社, $2006 \circ$ Amartya S K. Consequential Evaluation and Practical Reason, translated by YING Qi (Beijing: The Eastern Publishing Co., Ltd, 2006).

Anderson, Joshua. "Character Consequentialism: Confucianism, Buddhism, and Mill," Journal of Indian Philosophy and Religion 16:138-153. doi: 10.5840/jipr2011166, 2011.

Angle, Stephen C., and Michael A. Slote, eds. Virtue Ethics and Confucianism (New York: Routledge, 2013).

Anscombe, G. E. M. "Modern Moral Philosophy," Philosophy 33 (124):1-19. doi: 10.1017/S0031819100037943, 1958.

Berlin, Isaiah. "Two Concepts of Liberty," The Proper Study of Mankind: An Anthology of Essays (New York: Farrar, Straus and Giroux, 1969), pp. 197-242.

Chan, Benedict S. B. "Are International Human Rights Universal? East-West Philosophical Debates on Human Rights to Liberty and 
Health," Metaphysics of Human Rights 1948-2018: On the Occasion of the 70th Anniversary of the UDHR, edited by Luca Di Donato and Elisa Grimi (Malaga, Spain: Vernon Press, 2019), pp. 135-152.

Chan, Benedict S. B. "East Asia: Challenges to Political Rights," Routledge Handbook of Development Ethics, edited by Jay Drydyk and Lori Keleher (New York: Routledge, 2019), pp. 382-386.

Chang, Carson, Yu-wei Hsieh, Foo-kwan Hsu, Chung-san Mou, and Chun-i T'ang. "A Manifesto on the Reappraisal of Chinese Culture," Essays on Chinese Philosophy and Culture, edited by Chun-i T'Ang, (Taiwan: Student Book Co., Ltd., 1958), pp. 492-562.

Cummiskey, David. Kantian Consequentialism (Oxford University Press, 1996).

Dawson, Angus. "Herd Protection as a Public Good: Vaccination and our Obligations to Others," Ethics, Prevention, and Public Health, edited by Angus Dawson and Marcel Verweij (Oxford: Oxford University Press, 2007), pp. 160-178.

Delmas, Candice. "Samaritanism and Civil Disobedience," Res Publica 20 (3):295-313. doi: 10.1007/s11158-014-9249-7, 2014.

Drydyk, Jay, and Lori Keleher, eds. Routledge Handbook of Development Ethics (New York: Routledge, 2019).

D'Ambrosio, Paul. "The Value of Falsity in the Mencius: Early Confucianism is not Consequentialism," International Communication of Chinese Culture 2 (2):137-145. doi: 10.1007/s40636-015-0017-y, 2015.

Fan, Ruiping, ed. Confucian Bioethics (Dordrecht: Kluwer Academic Publishers, 1999).

Fan, Ruiping. Reconstructionist Confucianism: Rethinking Morality after the West (Dordrecht, Netherlands: Springer, 2010).

Ferguson, N, D Laydon, G Nedjati Gilani, N Imai, K Ainslie, M Baguelin, S Bhatia, A Boonyasiri, Z Cucunuba Perez, G Cuomo-Dannenburg, A Dighe, I Dorigatti, H Fu, K Gaythorpe, W Green, A Hamlet, W Hinsley, L Okell, S Van Elsland, H Thompson, R Verity, E Volz, H Wang, Y Wang, P Walker, C Walters, P Winskill, C Whittaker, C Donnelly, S Riley, and A Ghani. 2020. "Impact of non-pharmaceutical interventions (NPIs) to reduce COVID-19 mortality and healthcare demand," Imperial College London, Last Modified Imperial College London, accessed March 16. https://doi.org/10.25561/77482.

Im, Manyul. "Mencius as Consequentialist," Ethics in Early China: An Anthology, edited by Chris Fraser, Dan Robins and Timothy O'Leary (Hong Kong: Hong Kong University Press, 2011), pp. 41-63.

Ivanhoe, Philip. "Character Consequentialism: An Early Confucian Contribution to Contemporary Ethical Theory," Journal of Religious Ethics 19 (1):55-70, 1991.

Keown, Damien. "Karma, Character, and Consequentialism," Journal of Religious Ethics 24 (2):329-350, 1996.

Macintyre, Alasdair. "Incommensurability, Truth, and the Conversation between Confucians and Aristotelians about the Virtues," Culture and Modernity: East-West Philosophic Perspectives, edited by Eliot Deutsch (Honolulu: University of Hawaii Press, 1991), pp.104-122. 
Malone, Kevin M., and Alan R. Hinman. "Vaccination Mandates: The Public Health Imperative and Individual Rights," Law in Public Health Practice, edited by Richard A. Goodman, Richard E. Hoffman, Wilfredo Lopez, Gene W. Matthews, Mark A. Rothstein and Karen L. Foster (Oxford: Oxford University Press, 2007), pp. 338-360.

Mill, John $\quad$ Stuart. $1863 . \quad$ Utilitarianism: https://en.wikisource.org/wiki/Utilitarianism.

Nozick, Robert. Anarchy, State, and Utopia (New York: Basic Books, Inc, 1974).

Nussbaum, Martha. "Nature, Functioning and Capability: Aristotle on Political Distribution," Oxford Studies in Ancient Philosophy (Supplementary Volume) 6:145-184, 1998.

Nussbaum, Martha. Women and Human Development (Cambridge: Cambridge University Press, 2000).

Nussbaum, Martha. "Comment," Goodness and Advice, edited by Amy Gutmann (Princeton, N.J.: Princeton University Press, 2001), pp. 97-125.

Nussbaum, Martha. Frontiers of Justice: Disability, Nationality, Species Membership (Cambridge, MA: Belknap Press of Harvard University Press, 2006).

Nussbaum, Martha. Creating Capabilities: the Human Development Approach (Cambridge, MA: Belknap Press of Harvard University Press, 2011).

O' Neill, Onora. "The Dark Side of Human Rights," International Affairs 81 (2):427-439. doi: 10.1111/j.1468-2346.2005.00459.x, 2005.

Qizilbash, Mozaffar. “Amartya Sen's Capability Approach: Insightful Sketch or Distorted Picture?" The Capability Approach: Concepts, Measures and Applications, edited by Flavio Comim, Mozaffar Qizilbash and Sabina Alkire (Cambridge: Cambridge University Press, 2008), pp. 53-81.

Rawls, John. Political Liberalism (Columbia University Press, 1993).

Robeyns, Ingrid. "Capabilitarianism," Journal of Human Development and Capabilities 17 (3):397-414. doi: 10.1080/19452829.2016.1145631, 2016.

Robeyns, Ingrid. Wellbeing, Freedom and Social Justice: The Capability Approach Re-Examined (Cambridge, UK: Open Book Publishers, 2017).

Ruger, Jennifer Prah. Health and Social Justice (Oxford: Oxford University Press, 2010).

Scheffler, Samuel, ed. Consequentialism and Its Critics (Oxford: Oxford University Press, 1988).

Scheffler, Samuel. The Rejection of Consequentialism: A Philosophical Investigation of the Considerations Underlying Rival Moral Conceptions, edited by Press Oxford University. Rev. ed. (Oxford: Oxford University Press, 1994).

Sen, Amartya. "Utilitarianism and Welfarism," Journal of Philosophy 76 (9):463-489, 1979. 
Sen, Amartya. "Equality of What?" Tanner Lectures on Human Values, edited by Sterling McMurrin (Cambridge: Cambridge University Press, 1980), pp. 195-220.

Sen, Amartya. "Rights and Agency," Philosophy \& Public Affairs 11 (1):3-39, 1982.

Sen, Amartya. "Rights and Capabilities," Resources, Values, and Development (Blackwell, 1984), pp. 307-324.

Sen, Amartya. Commodities and Capabilities (Amsterdam: Amsterdam University Press, 1985).

Sen, Amartya. Inequality Reexamined (Cambridge, MA: Harvard University Press, 1992).

Sen, Amartya. "Capability and Well-Being," The Quality of Life, edited by Martha Nussbaum and Amartya Sen (Oxford: Oxford University Press, 1993), pp. 30-53.

Sen, Amartya. "Maximization and the Act of Choice," Econometrica 65 (4):745-779. doi: 10.2307/2171939, 1997.

Sen, Amartya. Development as Freedom (New York: Knopf, 1999.).

Sen, Amartya. "Consequential Evaluation and Practical Reason," Journal of Philosophy 97 (9):477-502. doi: 10.2307/2678488, 2000.

Sen, Amartya. "Elements of a Theory of Human Rights," Philosophy and Public Affairs 32 (4):315-356, 2004.

Sen, Amartya. "Human Rights and Capabilities," Journal of Human Development 6 (2):151-166. doi: 10.1080/14649880500120491, 2005.

Sen, Amartya. "What Do We Want from a Theory of Justice?" Journal of Philosophy 103 (5):215-238. doi: 10.5840/jphil2006103517, 2006.

Sen, Amartya. The Idea of Justice (Cambridge, Mass.: Belknap Press of Harvard University Press, 2009).

Sen, Amartya. "A better society can emerge from the lockdowns," Financial Times, 2020a.

https://www.ft.com/content/5b41ffc2-7e5e-11ea-b0fb-13524ae1056b? fbclid=IwAR2FmuCJfoeIIKnINmHWUwTBsi2vJooYPFdA01Q59m VCXbF451BqyT6-Tjo.

Sen, Amartya. "Overcoming a pandemic may look like fighting a war, but the real need is far from that," The Indian Express, $2020 \mathrm{~b}$. https://indianexpress.com/article/opinion/columns/coronavirus-india-1 ockdown-amartya-sen-economy-migrants-6352132/.

Singer, Peter. "Famine, Affluence, and Morality," Philosophy \& Public Affairs 1 (3):229-243, 1972.

Slote, Michael. "The Philosophical Reset Button: A Manifesto," Dao 14 (1):1-11. doi: 10.1007/s11712-014-9413-y, 2015.

Smart, J. J. C., and Bernard Williams. Utilitarianism: For and Against, edited by Bernard Williams (Cambridge: Cambridge University Press, 1973).

Sreenivasan, Gopal. "A Human Right to Health? Some Inconclusive Scepticism," Proceedings of the Aristotelian Society, Supplementary Volume 86 (1):239-265. doi: 10.1111/j.1467-8349.2012.00216.x, 2012.

Thomson, Judith Jarvis. Goodness \& Advice, edited by Amy Gutmann (Princeton: Princeton University Press, 2001). 
Tillman, Hoyt Cleveland. Utilitarian Confucianism: Ch'en Liang's Challenge to Chu Hsi (Cambridge, Mass: Council on East Asian Studies, Harvard University, 1982).

Van Norden, Bryan. Virtue Ethics and Consequentialism in Early Chinese Philosophy (Cambridge: Cambridge University Press, 2007).

Venkatapuram, Sridhar. Health Justice: an Argument from the Capabilities Approach (Cambridge: Polity, 2011).

Walker, P, C Whittaker, O Watson, M Baguelin, K Ainslie, S Bhatia, S Bhatt, A Boonyasiri, O Boyd, L Cattarino, Z Cucunuba Perez, G Cuomo-Dannenburg, A Dighe, C Donnelly, I Dorigatti, S Van Elsland, R Fitzjohn, S Flaxman, H Fu, K Gaythorpe, L Geidelberg, N Grassly, W Green, A Hamlet, K Hauck, D Haw, S Hayes, W Hinsley, N Imai, D Jorgensen, E Knock, D Laydon, S Mishra, G Nedjati Gilani, L Okell, S Riley, H Thompson, H Unwin, R Verity, M Vollmer, C Walters, H Wang, Y Wang, P Winskill, X Xi, N Ferguson, and A Ghani. 2020. "The global impact of COVID-19 and strategies for mitigation and suppression," Imperial College London, Last Modified March 26. https://doi.org/10.25561/77735.

Wellman, Christopher H. "Samaritanism and the Duty to Obey the Law," Is There a Duty to Obey the Law? edited by Christopher H. Wellman and A. John Simmons (Cambridge: Cambridge University Press, 2005), pp. 3-89.

Williams, Bernard, and Amartya Sen, eds. Utilitarianism and beyond (Cambridge: Cambridge University Press, 1982).

Wolff, Jonathan. "The Demands of the Human Right to Health," Proceedings of the Aristotelian Society, Supplementary Volume 86 (1):217-237. doi: 10.1111/j.1467-8349.2012.00215.x, 2012.

Yu, Jiyuan. "Virtue: Confucius and Aristotle," Philosophy East and West 48 (2):323-347. doi: 10.2307/1399830, 1998.

$\mathrm{Yu}$, Jiyuan. The Ethics of Confucius and Aristotle: Mirrors of Virtue (New York: Routledge, 2007).

Yunping, Wang. “Are Early Confucians Consequentialists?” Asian Philosophy 15 (1):19-34. doi: 10.1080/1463136042000328034, 2005. 